\title{
Considerations on the use of RIS records
}

\author{
Mihai GHIBA ${ }^{1, \mathrm{a}}$
}

${ }^{1}$ Department of Engineering and Management of Technological Systems, Faculty of Mechanics, University of Craiova, Calugareni Street 1, 220037, Drobeta Turnu Severin, Mehedinti, Romania

agomog44@yahoo.com

Keywords: RIS services, AIS standard, e-Logbook, e-SRB, safety requirements, accidents investigation, insurance, risk analysis

\begin{abstract}
This paper makes a comparative analysis of the data recorded and used in inland transport activity utlizand information that is recorded in "electronic ship reporting" and "Automatic Identification System" in the standard River Information Services - Vessel Traking and Tracing combined with those additionally recorded in the logbook and in the seafarer's service book. RIS recordings largely make the database necessary for keeping the Logbook, and differences can be evaluated through a matrix. The concentrated data set can be used to determine the working time of seafarers and establishing the compliance with promotion requirements based on the training fully recorded, to accumulate data necessary for shaping risk functions, to clarify the conditions under which shipping accidents occurred, with results in the recovery of losses by marine insurance, to a thorough and accurate risk analysis.
\end{abstract}

\section{Introduction}

We propose a comparative analysis of the records and evaluation of their usability possibilities, combined with the below listed situations:

- determination of seafarers'working time and establishment of the promotion requirements based on the fully registered training;

- the accumulation of RIS records in an ordered database that is created in the "electronic logbook"

- the clarification of the conditions under which shipping accidents occurred;

- the development of risk analysis for determining optimal navigation conditions;

- the achievement of water safety information.

Targeting the listed objectives, we have drawn a matrix of ship records for ERI, RIS component, for AIS, RIS-VTT component, for the Log book and the seafarer's service book. Since the volume of data covers a large amount, we reduced the matrix to the titles of groups records, as follows:

Table 1 Group of records

\begin{tabular}{|l|l|c|c|c|c|}
\hline No. & \multicolumn{1}{|c|}{ Titles of the group of records } & ERI & AIS & Logbook & SRB \\
\hline 1 & vessel identification data set & $\mathrm{X}$ & $\mathrm{X}$ & $\mathrm{X}$ & $\mathrm{X}$ \\
\hline 2 & voyage data & $\mathrm{X}$ & $\mathrm{X}$ & $\mathrm{X}$ & $\mathrm{X}$ \\
\hline 3 & information on dangerous goods & $\mathrm{X}$ & $\mathrm{X}$ & $\mathrm{X}$ & \\
\hline 4 & dynamic information & & $\mathrm{X}$ & & \\
\hline 5 & dimensions of the ship & $\mathrm{X}$ & $\mathrm{X}$ & & \\
\hline 6 & data on the position of AIS antenna & $\mathrm{X}$ & $\mathrm{X}$ & & \\
\hline 7 & dimensions of the ship & $\mathrm{X}$ & $\mathrm{X}$ & & \\
\hline 8 & displacement & & $\mathrm{X}$ & & \\
\hline 9 & AIS and radar auxiliary information & & $\mathrm{X}$ & & \\
\hline 10 & messages transmitted by AIS & $\mathrm{X}$ & $\mathrm{X}$ & & \\
\hline 11 & general data on ship & $\mathrm{X}$ & $\mathrm{X}$ & & \\
\hline 12 & record data on owners, charters, operators & $\mathrm{X}$ & $\mathrm{X}$ & & \\
\hline 13 & data on the sizes of the vessel or convoy & $\mathrm{X}$ & $\mathrm{X}$ & & \\
\hline 14 & data on tonnage & & $\mathrm{X}$ & & \\
\hline 15 & data on Engines and Hull & $\mathrm{X}$ & $\mathrm{X}$ & & \\
\hline 16 & data on goods & & & \\
\hline
\end{tabular}




\begin{tabular}{|c|c|c|c|c|c|}
\hline 17 & data on the crew and passengers - crew and passenger list & $\mathrm{X}$ & & $\mathrm{X}$ & $\mathrm{X}$ \\
\hline 18 & name of the commander and number of crew and passengers & & $\mathrm{X}$ & $\mathrm{X}$ & \\
\hline 19 & additional data on class/ice & & $\mathrm{X}$ & & \\
\hline 20 & data on voyage incidents & $\mathrm{X}$ & $\mathrm{X}$ & $\mathrm{X}$ & \\
\hline 21 & data on voyage diary & $\mathrm{X}$ & $\mathrm{X}$ & $\mathrm{X}$ & \\
\hline 22 & data on the navigation time & & & $\mathrm{X}$ & $\mathrm{X}$ \\
\hline 23 & data on the watchman & & & $\mathrm{X}$ & $\mathrm{X}$ \\
\hline 24 & modality of ship operation & & & $\mathrm{X}$ & $\mathrm{X}$ \\
\hline 25 & working and rest time & & & $\mathrm{X}$ & $\mathrm{X}$ \\
\hline 26 & data on the operation of engines consumptions & - & - & - & - \\
\hline 27 & data on the engine emissions & - & - & - & - \\
\hline
\end{tabular}

We note that AIS data covers almost all groups of records, except the data on crew found in ERI, in the Logbook and in the Service book of each crew member separately. For automatic calculation of training time, is necessary to combine data from position 17, data on crew-crew list with common data at position 2, voyage dates, and with those specific to AIS from position 4, dynamic information, navigation time. Time values obtained shall be attributed to each member of the crew and correlated with modality of ship operation by correlating the results with sections 22 , 24 and 25 .

We also note the repetition of data differently for each type of record. Thus the identification data of the vessel are default: vessel name, the single European - ENI and MMSI code are common data for each group of records. This allows the indexing of databases so that records to be performed for the same ship and electronic LogBook and e-SRB creation to be done separately for the same ship.

All ERI records are viable for setting the electronic logbook of the voyage. All AIS records, except those in sections 6 and 9, are also viable for the creation of the electronic logbook. Currently, the written logbook is focused on workflow records, of the personnel performing navigation watches and of possible incidents during navigation. It is still very important, given the opportunity, to use automatically recorded data to form a much more complete logbook and ie, besides those listed in paragraphs 18-25 and data the electronic map and those regarding navigation conditions.

The electronic map, ECDIS, stores data on vessel position in the fairway, data which, together with the direction and speed ones highlighted by AIS can clarify true evolution of the vessel on the navigation sector on which it operates. The interpretation of these data allow determining the causes of an accident, and besides that, the risk situations not resulting in damage. Correlating ECDIS-AIS data with those related to the navigation conditions, the reasons/circumstances in which certain incidents or accidents occur in navigation, can be determined. Proper determination of the grounds allows an objective assessment of the conditions and, thus, a clear definition of risks. The navigation conditions shall be determined by outlining the two groups of data:

- optimum condition in terms of navigation, ie concrete parameters of conditions have values that do not disturbe-hinder navigation (wind, visibility, current, gauges, traffic, etc.),

- the exceptional condition in terms of upper and lower limit values of parameters, which can demonstrate force majeure in the event of shipping accidents.

From this point of view, the evaluation of the capacity of tracking the navigation watch crew member, using tracking parameters. By tracking, we understand orientation by certain landmarks (signals, natural or artificial landmarks) with direct observation and on-board equipment, and assessment of conditions, so that the vessel is maintained permanently enrolled in navigable way regardless of the direction of navigation. Paragraphs 26 and 27 of the matrix are inserted as they are trends in the European Community to register emissions of ship engines, to set limit-standard on such emissions, to control maintenance programs of propulsion plants and for general objectives of environmental protection. 


\section{Technical solution for the utilisation of the RIS records}

Given these considerations and the fact that the matrix show duplicate records in both standards, we suggest:

- the use of "single window" for loading ERI and AIS common database, on a computer installed on board, under the provisions of Regulation EC 414/2007 art. 3.3

- the program used must select data necessary for creating e-LogBook, which will unerline, of course, the following applications:

$\circ$ personalization of watchkeeping for the purpose of recording the working and rest time under Directive 2003/88/EC, which sets out the minimum standards for the organization of working time for daily and weekly periods, number limits of weekly working time, the annual work time of day and night, rules aimed at sailors health and safety at work.

O calculating and recording the watch keeping time in e-SRB, the concerted initiative of the European Barge Union (EBU), the European Skippers Organisation (ESO) and the European Transport Workers' Federation (ETF) of developing a new EC Directive shall be considered, based on previous experiences, related to ork time in European inland transport,

0 storing the navigation information from ECDIS, AIS and NtS usable in case of maritime incidents or accidents that may become basic information for risk assessments,

O storing information on emissions,

- implementation of a database to be used in education programs, in order to achieve both basic knowledge and learning packages customized on difficult navigation areas - Local Knowledge Requirements (LKR).

\section{Conclusions}

We've made some considerations on the use of RIS records in order to improve the safety parameters of inland navigation. Further analysis of the entire RIS database on risk-safety criteria shall allow obtaining competent answers for:

- determining optimal navigational conditions,

- the safety limits for all parameters concerned,

- procedures for the control of risk parameters, which allows expansion of the safety conditions far beyond the existing limits.

In the inland water transport, an increased trend in transport of dangerous goods (AND), especially liquid and gaseous fuels and chemicals, is observed. It also aims at the partial replacement of conventional fuels for the engines of river ships with liquefied natural gas as fuel (Liquefied Natural Gas) requiring specialized crews and increased safety measures in its transport to bunker basis, bunkering and shipboard use. In this regard it is necessary to draft safety plans and in some cases, security plans for the control of risk parameters, function met by HAZIT teamHazard Identification Team. Under these conditions, RIS records are indispensable. Knowing the general expression:

$$
F_{\text {safety }}=1-F_{\text {risk }}
$$

and knowing that:

$$
F_{\text {safety }}=F_{\text {crew }}+F_{\text {ship }}+F_{\text {waterway }}=1-F_{\text {risk }}
$$

it results that the development of safety measures analysis will determine the reduction of the risk. More specifically, the degree of organization of the system approaches 1 if the degree of 
disorganization tends to zero. Considering the fact that risk cannot be eliminated, it should be reduced to the minimum acceptable risk level. RIS analysis and procedures focus on:

- quality of the crew - the expression aims at emphasizing that it is not enough only a good professional training and experience calculated through internship, but also professional awareness adequate to safety objectives;

- quality of the ship - the expressions highlights the extent to which the ship complies with the safety requirements for the type or types of goods for which it was designed but also the functioning modality in extreme conditions;

- quality of waterway - the term reveals both the assurance of navigation gauges and the possibility of using ECDIS in terms of maximum accuracy.

The first steps made by RoRIS 2 can be seen in the figure 1 .

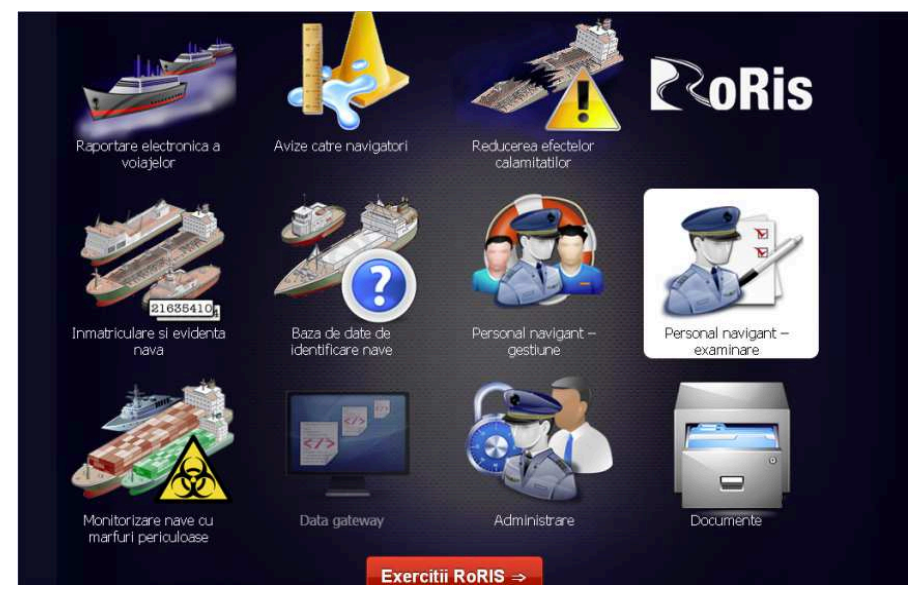

Fig.1 Romanian RIS web template

Observing the input possibilities, we conclude that the possibility of accessing the ERI database, the crew database and also the examination database is initiated. It is also noted that vessels transporting dangerous goods are separartely monitored, which corresponds to the risk control objectives. The window indicates the first steps towards the objectives of data use in the form discussed in this analysis.

\section{References}

[1] $]^{* * *}$ Directive 2003/88/EC of the European Parliament and of the Council of 4 November 2003 concerning certain aspects of the organisation of working time, OJ L 299, 18.11.2003, p. 9-19.

[2]Ghe. I.Cretu - Optimizing water management systems - Facla Publishing House 1980.

[3]M. Ghe.Ghiba - Danube water pollution resulting from naval transport activity - Universitaria Publishing House 2005-ISBN 973-742-031-4.

[4]M. Ghe. Ghiba - Improving risk control parameters through selective collection and quantified parameters efficient communication- Universitaria Publishing House - ISBN 978-606-14-0562-6 Craiova Romania 2012, pp.217-220.

[5]****Directive 2005/44/EC of the European Parliament and of the Council - of harmonised river information services (RIS) on inland waterways in the Community-OJ L 255-30 ${ }^{\text {th }}$ September 2005.

[6] M. Ghe. Ghiba- Assessment of the risk parameters and their use in the vessel traffic management - Modtech Conferrence 2013.

[7]**** Commission Regulation (EC) No 415/2007 of 13 March 2007 concerning the technical specifications for vessel tracking and tracing systems referred to in Article 5 of Directive 2005/44/EC of the European Parliament and of the Council on harmonised river information services (RIS) on inland waterways in the Community.

[8]**** Proposal for a COUNCIL DIRECTIVE implementing the European Agreement concluded by the European Barge Union (EBU), the European Skippers Organization (ESO) and the European Transport Workers' Federation (ETF) concerning certain aspects of the organization of working time in inland waterway transport - Brussels, 7.7.2014. 